\title{
Reflexões sobre a operacionalização do PNAE nas Escolas Estaduais de Passo Fundo (RS)
}

\author{
David Basso \\ Universidade Regional Noroeste do Estado do Rio Grande do Sul - ljui - Rio \\ Grande do Sul - Brasil \\ Indaia Dias Lopes \\ Universidade de Passo Fundo - UPF - Passo Fundo - Rio Grande do Sul - Brasil \\ Volmir Ribeiro do Amaral \\ Universidade Regional Noroeste do Estado do Rio Grande do Sul - ljui - Rio \\ Grande do Sul - Brasil
}

\section{Resumo}

O Programa Nacional de Alimentação Escolar (PNAE) é um dos maiores e mais antigos programas de alimentação escolar do mundo. A Lei $n^{\circ}$ 11.947/2009 tornou obrigatória a inclusão de produtos da agricultura familiar na alimentação escolar. A efetividade do PNAE depende de como ocorre a interação dos atores que fazem a gestão do programa no nível local. O objetivo deste trabalho é analisar a operacionalização do PNAE nas escolas estaduais de Passo Fundo em relação às aquisições da agricultura familiar. Agricultura familiar e mercados institucionais constituíram a base teórico-conceitual para a análise dos resultados. Trata-se de pesquisa explicativa, com abordagem qualitativa, com dados coletados por meio de entrevistas. As escolas estaduais de Passo Fundo utilizam a gestão escolarizada, onde cada escola administra os recursos da alimentação escolar. Entre agosto de 2014 e junho de 2016 as escolas estaduais de Passo Fundo utilizaram-se da Chamada Pública Unificada, conduzida pela $7^{\text {a }}$ Coordenadoria Regional de Educação, a partir das demandas individualizadas das escolas, para adquirir produtos da agricultura familiar. Até junho de 2013 e após agosto de 2016 este tipo de aquisições foi feito por meio de Chamadas Públicas Individuais. Dentre as conclusões do estudo, evidenciou-se que a realização das Chamas Públicas Unificadas qualificou a operacionalização do PNAE em Passo Fundo, facilitando a execução do programa para as escolas, ampliando a participação da agricultura familiar regional.

Palavras-Chave: Alimentação Escolar. Mercados Institucionais. Agricultura Familiar.

\footnotetext{
1 O presente trabalho foi realizado com apoio da Coordenação de Aperfeiçoamento de Pessoal de Nível Superior - Brasil (CAPES) - Código de Financiamento 001. O artigo traz um recorte da dissertação de um dos autores (LOPES, 2018) e foi construído a partir do diálogo e contribuições do autor e coautores.
} 


\title{
Reflections on the operationalization of the PNAE in the State Schools of Passo Fundo-RS
}

\begin{abstract}
The National School Feeding Program (PNAE) is one of the largest and oldest school feeding programs in the world. Law $\mathrm{n}^{\circ} 11.947 / 2009$ determined the compulsory inclusion of family farming products in school feeding. The effectiveness of the PNAE depends on how the interaction of the actors that manage the program at the local level occurs. The objective of this work is to analyze the operationalization of the PNAE in the state schools of Passo Fundo in relation to the acquisitions of family agriculture. Family agriculture and institutional markets constituted the theoretical-conceptual basis for the analysis of results. It is an explanatory research, with qualitative approach of the data, collected through interviews. The state schools of Passo Fundo use school management, where each school administers school feeding resources. Between August 2014 and June 2016, state schools used the Unified Public Call, conducted by the 7th Regional Education Coordination, based on the individualized demands of schools, to purchase products from family agriculture. Until the middle of 2014 and from August of 2016 this type of acquisitions was made through Individual Public Calls. Among the conclusions of the study it was evidenced that the implementation of the Unified Public Calls qualified the operationalization of the PNAE in this municipality, facilitating the execution of the program for the schools, increasing the participation of the regional family agriculture.
\end{abstract}

Keywords: School Feeding. Institutional Markets. Family Farming.

\section{Reflexiones sobre la operacionalización del PNAE en las Escuelas Estaduales de Passo Fundo-RS}

\section{Resumen}

El Programa Nacional de Alimentación Escolar (PNAE) es uno de los mayores y más antiguos programas de alimentación escolar del mundo. La Ley $n^{\circ}$ 11.947/2009 determinó la obligatoriedad de la inclusión de productos de la agricultura familiar en la alimentación escolar. La efectividad del PNAE depende de cómo ocurre la interacción de los actores que hacen la gestión del programa a nivel local. El objetivo de este trabajo es analizar la operacionalización del PNAE en las escuelas estaduales de Passo Fundo en relación a las adquisiciones de la agricultura familiar. La agricultura familiar y los mercados institucionales constituyeron la base teórico-conceptual para el análisis de los resultados. Se trata de una investigación explicativa, con enfoque cualitativo de los datos, recogidos por medio de entrevistas. Las escuelas estaduales de Passo Fundo utilizan la gestión escolarizada, donde cada escuela administra los recursos de la alimentación escolar. Entre agosto de 2014 a junio de 2016, las escuelas estaduales se utilizaron de la llamada pública unificada, conducida por la $7^{\text {a }}$ Coordinadora Regional de Educación, a partir de las demandas individualizadas de las escuelas, para adquirir productos de la agricultura familiar. Hasta la mitad de 2014 ya partir de agosto de 2016 este tipo de adquisiciones fue hecho por medio de Llamadas Públicas Individuales. Entre las conclusiones del estudio se evidenció que la realización de las Llamadas Públicas Unificadas calificó la operacionalización del PNAE en este municipio, facilitando la ejecución del programa para las escuelas ampliando la participación de la agricultura familiar regional.

Palabras-Clave: Alimentación Escolar. Mercados Institucionales. Agricultura familiar. 


\section{Introdução}

Em alguns países em desenvolvimento os Programas de Alimentação Escolar (PAEs) vêm sendo utilizados por mais de 50 anos como instrumento de combate a problemas de fome e pobreza. O Programa Mundial de Alimentos (PMA), da Organização das Nações Unidas (ONU), é o maior provedor mundial de alimentos para os PAEs, tendo desembolsado 442 milhões de dólares dos EUA em 2010 para beneficiar 22 milhões de estudantes em todo o mundo (SONNINO; SPAYDE; ASHE, 2016).

Nesse cenário, o PMA tenta incentivar a substituição dos alimentos importados pelos alimentos que são cultivados localmente. Tal iniciativa tem como objetivo principal constituir mercados direcionados aos produtores locais, articulados à promoção da saúde e educação dos alunos (MORGAN; SONINNO, 2010) e é considerado como um instrumento de desenvolvimento (SONNINO; SPAYDE; ASHE, 2016).

Neste contexto, o Programa Nacional de Alimentação Escolar (PNAE) brasileiro vêm sendo utilizado como uma referência para outros países da América Latina e Caribe em termos de estrutura organizativa (ONU, 2017). O PNAE é um programa de alimentação escolar que objetiva, em caráter suplementar, a transferência de recursos financeiros pelo Fundo Nacional de Desenvolvimento da Educação (FNDE) aos estados, ao Distrito Federal (DF) e aos municípios, visando suprir parcialmente as necessidades nutricionais dos alunos. Os beneficiários do PNAE são, portanto, os alunos de toda a educação básica: educação infantil, ensino fundamental, ensino médio e Educação de Jovens e Adultos (EJA), matriculados em escolas públicas, filantrópicas e em entidades comunitárias conveniadas com o poder público (FNDE, 2016).

A viabilização das políticas de compras institucionais de alimentos da agricultura familiar para a alimentação escolar necessita de estratégias e de concertações para potencializar a interação entre os atores locais (BALEM, 2015), as quais devem ser construídas levando em consideração a realidade de cada local e orientadas pelo envolvimento dos diferentes atores que fazem a operacionalização do programa. De acordo com Triches e Baccarin (2016), é no nível local, com base na conscientização e liderança dos gestores, profissionais técnicos e da participação da sociedade civil, que se pode garantir efetividade a tudo o que estabelece a legislação federal do PNAE.

A Lei n $11.947 / 2009$, em seu artigo 14, dispõe que, no mínimo $30 \%$ dos recursos do FNDE, no âmbito do PNAE, sejam investidos em produtos da agricultura familiar e do empreendedor familiar rural ou de suas organizações (BRASIL, 2009).

Desta forma, o Estado brasileiro buscou aproximar a agricultura familiar à alimentação escolar, no entanto, têm sido observadas dificuldades de alguns municípios em cumprir este dispositivo legal pelo fato de não ter havido o devido preparo dos produtores rurais para poderem suprir a necessidade das escolas (TERRA E SILVA; NATIVIDADE; JOAQUIM, 2016).

Diversos autores (TRICHES, 2010; AMARAL, 2016; BELIK, 2016a; FERNANDES; SCHNEIDER; TRICHES, 2016; WAGNER; GEHLEN; SCHULTZ, 2016) vêm direcionando seus estudos no intuito de compreender esta aproximação entre alimentação 
escolar, agricultura familiar e desenvolvimento local pretendida pelo PNAE, especialmente a partir das alterações introduzidas em 2009.

Com o intuito de contribuir para as discussões acerca do PNAE, este artigo tem por objetivo analisar como ocorre a operacionalização deste programa nas escolas estaduais do município de Passo Fundo, localizado no norte do Estado do RS, no que diz respeito às aquisições de produtos da agricultura familiar.

A escolha deste município enquanto lócus de pesquisa justifica-se por esta ser a maior cidade do norte do RS, com uma população de aproximadamente 198.799 habitantes (IBGE, 2017), que possui 39 escolas estaduais que atendem em torno de 15.764 alunos e recebem do FNDE aproximadamente $\mathrm{R} \$ 3$ milhões ao ano em recursos para a alimentação escolar, se constituindo em um importante e potencial mercado para a agricultura familiar.

Este artigo está organizado em cinco seções. Além desta introdução, que evidencia a importância do PNAE enquanto programa de alimentação escolar e mercado potencial para agricultores familiares, na segunda seção apresenta-se uma síntese do debate teórico acerca de mercados institucionais e agricultura familiar. A terceira seção trata dos aspectos metodológicos orientadores do estudo. Na quarta seção é feita uma caracterização do município de Passo Fundo, apresentando os principais dados de sua rede escolar estadual, assim como destacados os principais aspectos do PNAE nas escolas selecionadas e a percepção dos atores sociais envolvidos na operacionalização do Programa. Por fim, segue-se as considerações finais.

\title{
2 Mercados institucionais e agricultura familiar
}

Os mercados institucionais, como os que envolvem o PNAE, podem ser analisados pelo olhar da sociologia econômica, que considera os mercados como construções sociais, e não apenas como resultado de interações das forças privadas, mediadas pelo mecanismo de formação dos preços, com regulação apenas das quantidades ofertadas e demandadas, fornecendo, assim uma base teóricoconceitual para compreender e explicar as relações do PNAE com o desenvolvimento local ou regional.

Nesta perspectiva, Granovetter (2007, p. 10) argumenta que:

\begin{abstract}
os atores não se comportam nem tomam decisões como átomos fora de um contexto social, e nem adotam de forma servil um roteiro escrito para eles pela intersecção específica de categorias sociais que eles porventura ocupem. Em vez disso, suas tentativas de realizar ações com propósito estão imersas em sistemas concretos e contínuos de relações sociais.
\end{abstract}

Abramovay (2001, p. 167) sustenta igualmente que mercados são "construções sociais que refletem o ambiente institucional em que se inserem e não simplesmente sistemas universais de formação de preços". Para o autor, compreender os mercados institucionais como estruturas sociais, em que o funcionamento depende dos ambientes institucionais em que estão inseridos, constitui importante contribuição do pensamento institucionalista. Para Ploeg (2016), os mercados envolvem relações sociais, as quais podem ser visíveis ou completamente desconhecidas. 
Argumentando que o homem é um ser social e que suas atitudes são direcionadas para manter sua situação social, Polanyi (1980, p. 61) afirma que "nem o processo de produção, nem o de distribuição está ligado a interesses econômicos específicos relativos à posse de bens. Cada passo desse processo está atrelado a certo número de interesses sociais".

No tocante aos mercados, Schneider (2017) destaca que eles devem ser compreendidos como formas de interação entre os atores sociais e não como algo metafísico ou abstrato. Os mercados públicos e institucionais são resultados da construção social e política, tem origem em recursos públicos, os quais provêm de contribuições públicas. Estes mercados são criados para atender a determinadas demandas, tais como a da alimentação escolar, de hospitais, de cestas básicas e seus funcionamentos podem ser realizados mediante um controle mais ou menos aberto (SCHNEIDER, 2016).

Para Grisa e Porto (2015), a alimentação escolar institucionalizou-se com o PNAE no final dos anos 1970. O governo federal centralizou o gerenciamento e aquisição de alimentos neste mercado até a década de 1990, quando então teve início a descentralização dos recursos, ficando sob a responsabilidade dos estados e municípios a elaboração dos cardápios, a aquisição dos alimentos e o controle de qualidade (TRICHES, 2010).

Se, por um lado, a descentralização favorecia a aquisição de alimentos locais e frescos, por outro, o mercado institucional de alimentação escolar continuava sendo executado por meio de licitação (Lei $n^{\circ}$ 8.666/1993), com a aquisição de gêneros alimentares baseados no princípio da economicidade da Constituição Federal, muitas vezes industrializados, desvinculados da produção alimentar local e que beneficiavam as empresas que conseguiam se manter mais competitivas nas licitações (GRISA; PORTO, 2015). Segundo os autores, com a descentralização foi possível que empresas de menor porte tivessem acesso ao mercado institucional de alimentação escolar, mas ainda faltava apoio à agricultura local, em especial aos agricultores familiares e também para uma alimentação mais saudável.

De acordo com Maluf (2007, p. 132):

o chamado mercado institucional, que compreende as compras de alimentos para programas governamentais como o da alimentação escolar, representa uma parcela expressiva da demanda e pode também cumprir papel destacado na dinamização da produção de alimentos de pequena e média escala e, portanto, integrar estratégias de desenvolvimento no âmbito local.

A possibilidade de articular produtores locais e consumidores de alimentos traz benefícios para ambos os envolvidos, por um lado reduz os gastos com transportes, por outro facilita a oferta de alimentos de qualidade e hábitos de consumo mais diversificados (MALUF, 2007). Neste contexto, o Estado possui um papel importante no sentido de criar programas que estimulem a interação entre estes atores sociais e que também estimulem a economia local das regiões envolvidas.

Schneider (2016) destaca que os mercados públicos e institucionais vêm sendo ocupados de forma crescente por agricultores familiares no Brasil e também em outros países do mundo, tendo como principal agente o Estado ou um organismo 
público. O referido autor afirma que, nestes mercados, os preços pagos pela demanda possuem uma tendência de serem mais elevados do que os preços praticados pelos mercados convencionais, o que desperta grande interesse por parte dos agricultores familiares, além de existir, geralmente, garantia de receber 0 pagamento pelos produtos vendidos.

O Estado possui importante papel no abastecimento alimentar e nas políticas de segurança alimentar e pode atuar em setores em que os mercados enfrentam dificuldades (SCHNEIDER, 2017). Assim sendo, o governo brasileiro, ao implementar a Lei $n^{\circ} 11.947 / 2009$, utilizou das compras públicas para beneficiar a alocação dos agricultores familiares locais aos mercados institucionais de alimentação escolar (TRICHES, 2015). Ainda existem entraves operacionais, estruturais, políticos e econômicos que devem ser enfrentados na construção e gerenciamento desse mercado, mas cabe ressaltar que a ação e relação entre os atores sociais envolvidos no processo de aquisição pública é um dos aspectos fundamentais para que a legislação tenha ou não efetividade.

Segundo Triches (2015), a mudança na legislação em 2009, tornando obrigatória a inclusão do agricultor familiar como fornecedor da alimentação escolar, beneficiou os alunos que recebem estes alimentos, os agricultores e também o meio ambiente, além disso, vários municípios vêm utilizando mais de 30\% dos seus recursos em alimentação escolar para aquisição de produtos com origem da agricultura familiar. Para esta autora, o Brasil foi um dos primeiros países a estabelecer políticas de alimentação escolar transformando o PNAE em uma estratégia de desenvolvimento local sustentável, beneficiando diretamente agricultores familiares localizados em ambientes mais próximos às escolas demandantes.

\section{Metodologia}

Este estudo configura-se como uma pesquisa aplicada. Quanto ao nível, tratase de uma pesquisa explicativa, em razão de que procura identificar que elementos auxiliam para os fenômenos acontecerem (GIL, 2016). É uma pesquisa de campo, considerado principal meio para compreender o objeto de estudo e encontrar explicações para responder aos objetivos propostos, utilizando-se do método abdutivo (CHIBENI, 1996), numa perspectiva descendente, a partir de aproximações sucessivas da realidade, em busca da melhor explicação para o objeto de estudo em sua totalidade (BASSO, 2012).

Quanto à abordagem dos dados, trata-se de uma pesquisa qualitativa (MINAYO, 2016), que busca conteúdos explicativos especialmente em dados primários, ainda que se servindo de dados secundários para subsidiar qualitativamente a análise.

Em razão do volume de dados gerados e pelo tipo de pesquisa (pesquisa de campo) foram selecionadas onze escolas estaduais, dentre as 39 existentes no município de Passo Fundo. Estas escolas foram selecionadas na perspectiva de incluir uma representação adequada da diversidade presente na realidade investigada, contemplando especialmente o número de alunos e a localização. Foram utilizados nomes fictícios para representar as escolas, procurando preservar a identidade dessas instituições e dos informantes-chave entrevistados. 
Os dados foram coletados por meio de entrevistas abertas com os atores envolvidos com a alimentação escolar. Os sujeitos da pesquisa foram selecionados dentre os indivíduos que possuem relação direta no planejamento e na operacionalização da compra de alimentos da agricultura familiar, bem como no preparo dos mesmos para a alimentação escolar nas escolas estaduais do município de Passo Fundo. Dentre esses indivíduos foram entrevistados os seguintes

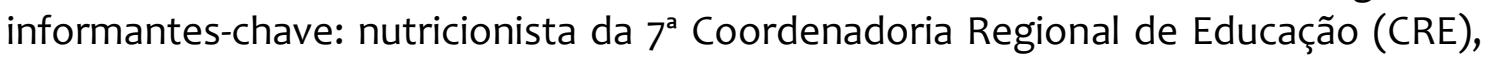
diretoras de escola, merendeiras, funcionários responsáveis pelas compras nas escolas, extensionistas da Emater municipal e representantes das cooperativas de agricultores familiares. Os informantes-chave entrevistados foram identificados da seguinte forma: nutricionista $(\mathrm{N})$, merendeiras $(\mathrm{M})$, diretoras, professoras ou funcionárias das escolas responsáveis pela aquisição da alimentação escolar (D), extensionistas da Emater regional e municipal de Passo Fundo (E) e representantes das cooperativas de agricultores familiares (AF). No total, foram realizadas 22 entrevistas abertas orientadas por um roteiro de entrevista. A pesquisa foi realizada entre os meses de março a novembro de 2017. As entrevistas foram gravadas com o auxílio do aparelho celular de um dos autores. As gravações foram transcritas na íntegra e, após, salvas de forma individual em um arquivo eletrônico Word®.

Os dados foram analisados e interpretados por meio do método de Análise de Situações de Desenvolvimento (ASD), o qual tem como base as pesquisas realizadas por Silva Neto (2007) e Basso (2012) que, por sua vez, apoiam-se epistemologicamente nas contribuições do realismo crítico de Bhaskar (2008) e no materialismo histórico e dialético (SILVA NETO, 2016) e operacionalmente na AnáliseDiagnóstico de Sistemas Agrários (DUFUMIER, 2007; MAZOYER \& ROUDART, 2010). Para realizar este tipo de análise o pesquisador deve priorizar o contato direto com a realidade, procurando compreender o que se propõe a estudar (BASSO, 2012). Cada nível de estudo deve ser analisado separada e progressivamente, por meio de observações e falas de indivíduos selecionados a priori à realização de cada etapa no desenvolvimento da pesquisa de campo, de forma que sejam respondidas as questões mais relevantes de cada etapa. Quando as principais questões de cada nível forem respondidas deve então ser realizada uma síntese daquele nível, procurando identificar as questões pertinentes para o próximo nível. O foco deve ser dado às informações com maior poder de explicação, de modo que se tenha maior poder explicativo do objeto de estudo (SILVA NETO, 2007).

\section{Resultados e discussão}

O objetivo desta seção é descrever e analisar os dados coletados sobre o PNAE na rede escolar estadual de Passo Fundo e interpretá-los à luz dos conceitos de mercados institucionais e agricultura familiar. Inicialmente é realizada uma caracterização do município de Passo Fundo, apresentando dados da rede escolar estadual local. No item 4.2 é traçado um panorama da atual situação da alimentação escolar nas escolas estaduais. Apresenta-se no item 4.3 a visão dos principais gestores e atores que atuam na operacionalização do PNAE sobre os resultados alcançados com este programa no município.

\subsection{O município de Passo Fundo e a rede escolar estadual}


O município de Passo Fundo localiza-se no norte do Estado do RS, sendo considerada uma cidade de porte médio, com uma população estimada em 198.799 habitantes e uma área de 783,421 km² (IBGE, 2017), com 90\% de sua área rural, $60 \% \mathrm{da}$ qual destinada à produção de milho, trigo e soja e os outros $30 \%$ utilizados para atividades como a avicultura, bovinocultura de leite e a horticultura (ALBRECHT et al., 2015).

Em 2015, Passo Fundo possuía um Produto Interno Bruto (PIB) per capita de $\mathrm{R} \$ 39.737,73$ (IBGE, 2017), acima da média do RS, que era de $\mathrm{R} \$ 33.960,36$ no mesmo ano (FEE, 2017). A economia do município é relativamente diversificada e apresenta um perfil mais voltado às atividades industriais e de serviços.

O setor educacional público estadual de Passo Fundo é composto por 39 escolas, as quais estão sob responsabilidade da $7^{a}$ CRE do RS. Apenas em janeiro de 2017 esta coordenadoria passou a contar com uma nutricionista, a qual tem uma carga horária de 40 horas semanais destinadas às atividades relacionadas a alimentação escolar em todos os 32 municípios de sua abrangência. Esta funcionária faz visitas nas escolas verificando as condições das instalações das cozinhas, refeitórios, depósitos de alimentos e de cumprimento das normas do PNAE.

O PNAE possui uma coordenação centralizada nacionalmente no FNDE e sua execução é descentralizada através das Entidades Executoras² (EEx). A presença do PNAE em todos os estados e municípios do País confere-lhe capilaridade nacional, possibilitando a constituição de diferentes modelos operacionais. Cada EEx responsabiliza-se pela execução do PNAE em suas respectivas redes de ensino. Mesmo o PNAE possuindo um modus operandi já bastante consolidado, sua execução é um tanto complexa, em função de envolver diversos agentes (poder público, órgãos de fiscalização e sociedade civil) nos níveis nacional, estadual e municipal.

Com relação às modalidades de gestão do PNAE, o Governo Federal, por meio do FNDE, transfere os recursos da alimentação escolar às EEx, e estas são responsáveis por definir a forma de gestão. A gestão do PNAE pode ser feita de três formas (TCU, 2017): a) centralizada, modalidade onde a EEx realiza as compras e faz a distribuição dos alimentos para as escolas; esse é o modelo mais adotado nos municípios brasileiros e é o modelo utilizado para as escolas municipais de Passo Fundo, com a Secretaria Municipal de Educação exercendo a função de EEx; b) semidescentralizada, caso onde a EEx - normalmente uma Secretaria Municipal ou Coordenadoria Estadual - faz as compras de alguns gêneros alimentícios, distribui para as escolas, e repassa parte do recurso financeiro para que cada escola faça a aquisição dos outros tipos de alimentos, em especial os adquiridos da agricultura familiar; e, c) descentralizada ou escolarizada, situação em que a EEx recebe do FNDE os recursos e os repassa integralmente às escolas para que estas, como Unidades Executoras (UEx), façam as aquisições de todos os produtos para a alimentação escolar, conforme a Figura 1.

\section{Figura 1 - Gestão do PNAE descentralizada.}

\footnotetext{
${ }^{2}$ As Entidades Executoras (EExs) incluem os estados e o Distrito Federal, os municípios e as escolas federais de educação básica. As EExs, mediante o recebimento dos recursos executam o PNAE em suas respectivas redes escolares, utilizando-se das formas operacionais previstas na legislação em vigor. Cada EEx responsabiliza-se pela execução do PNAE em suas respectivas redes de ensino.
} 

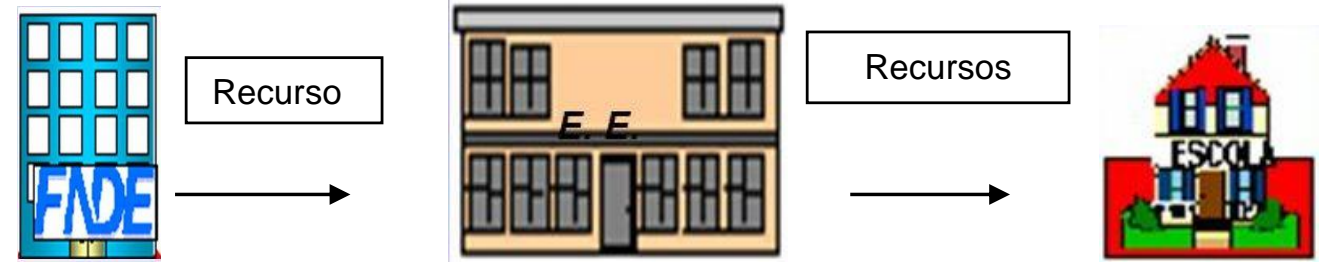

Fonte: Adaptado de Soares et al. (2013).

Este modelo escolarizado é bastante utilizado nas escolas das redes estaduais do País e é utilizado nas escolas estaduais de Passo Fundo.

Os recursos financeiros para a compra da alimentação escolar são repassados, anualmente, pelo FNDE, em dez parcelas, para a Secretaria Estadual de Educação (EEx), a qual os repassa integralmente, também em dez parcelas, para as direções das escolas (SEDUC-RS, 2016). O valor per capita diário transferido pelo FNDE às EEx varia conforme a modalidade de ensino e contempla 200 dias letivos por ano, como demonstrado no Quadro 1. O volume total de recursos leva em conta o número de alunos matriculados no ano anterior em cada modalidade de ensino.

Quadro 1 - Valor per capita por dia letivo transferido pelo FNDE às EEx de acordo com a modalidade de ensino.

\begin{tabular}{|c|c|}
\hline Modalidade de ensino & Valor (R\$) per capita \\
\hline Creches & 1,07 \\
\hline Pré-escola & 0,53 \\
\hline Escolas localizadas em áreas indígenas ou de quilombolas & 0,64 \\
\hline Ensino fundamental e médio & 0,36 \\
\hline Educação de Jovens e Adultos (EJA) & 0,32 \\
\hline Ensino integral & 1,07 \\
\hline Alunos do Programa Mais Educação & 1,07 \\
\hline Alunos que frequentam o atendimento especializado no contraturno & 0,53 \\
\hline
\end{tabular}

Fonte: FNDE (2017).

O Governo do Estado do RS realiza complementação nos valores por dia letivo por aluno nos casos de escolas estaduais que: a) oferecem Ensino Médio 1.000 horas, com complemento de R\$0,60 por aluno; b) possuem até 100 alunos, com complemento de $\mathrm{R} \$ 0,60$ por aluno e, c) oferecem ensino em tempo integral, com complemento de $\mathrm{R} \$ 1,07$ por aluno.

\subsection{A alimentação escolar nas Escolas Estaduais de Passo Fundo}

As compras para alimentação das escolas estaduais de Passo Fundo até o ano de 2009 eram realizadas somente via Licitação (Lei n 8666/1993), sendo considerado o menor preço e não eram adquiridos gêneros alimentícios de agricultores familiares. A Lei $n^{\circ} 11.947 / 2009$ trouxe avanços e mudanças para o PNAE, como a extensão do programa para toda a rede pública de educação básica e a garantia de, no mínimo, $30 \%$ dos recursos repassados pelo FNDE para adquirir produtos da agricultura familiar (FNDE, 2016). Dessa forma as escolas precisaram se estruturar para atender as diretrizes da nova legislação.

Além do processo licitatório, que as escolas já realizavam na compra dos produtos para a alimentação escolar no mercado local, a mudança na legislação em 2009 exigiu que o funcionário responsável por este processo também absorvesse as 
tarefas inerentes à aquisição de alimentos da agricultura familiar, envolvendo a elaboração de um instrumento de compra denominado de Chamada Pública3.

Nas Chamadas Públicas são divulgadas as demandas de produtos da agricultura familiar de cada escola. Sua divulgação ocorre por meio de jornais locais ou murais públicos e fica sob a responsabilidade dos agricultores ou cooperativas/associações de agricultores familiares a observância dos prazos e exigências que constam do edital.

De acordo com Fernandes, Schneider e Triches (2016), as mudanças ocorridas na forma de execução do PNAE introduzidas a partir de 2009 provocaram a necessidade de adequações nas estruturas físicas de preparo, armazenamento e conservação de alimentos e também no número de funcionários das escolas.

A articulação entre os atores locais da alimentação escolar com os fornecedores da agricultura familiar, envolvendo as escolas estaduais de Passo Fundo, só teve início no ano de 2013 , contando para isso com o envolvimento da $7^{\text {a }}$ CRE, da Emater/RS e de cooperativas de agricultores familiares. Os dados das entrevistas feitas junto aos atores envolvidos na operacionalização do PNAE neste município revelam que, até o segundo semestre de 2014, a gestão das aquisições de alimentos da agricultura familiar para a rede escolar estadual de Passo Fundo era feita a partir de Chamadas Públicas Individuais, ou seja, cada escola fazia as suas compras individualmente.

Este processo realizado a partir de cada escola gerava dificuldades para os diferentes atores sociais envolvidos na gestão do Programa. Por parte das cooperativas, era difícil identificar a demanda total das escolas, além da burocracia e custos envolvidos para poderem se habilitar às chamadas de cada escola; pelo lado das escolas, existiam dificuldades em mapear os fornecedores e os produtos da agricultura familiar, resultando no não atendimento da legislação (art. 14, Lei $n^{\circ}$ 11.947/2009).

Até o ano de 2013 a aproximação entre a Assistência Técnica e Extensão Rural e Social (ATERS), cooperativas de agricultores familiares e escolas estaduais, era irrelevante neste município, tornando difícil o acesso ao mercado institucional da alimentação escolar. As escolas reclamavam de irregularidade e falta de pontualidade nas entregas dos alimentos pelos agricultores familiares, não existiam fornecedores locais e havia problema nas embalagens e acondicionamento dos alimentos entregues pelos agricultores. Tais problemas apontavam para a necessidade de construção de estratégias de enfrentamento das barreiras existentes para a operacionalização do PNAE.

Sobre a importância da atuação da Aters para os mercados institucionais no Brasil, Niederle (2017, p. 191) destaca que:

De modo geral, os novos mercados têm se constituído como o resultado do esforço de uma rede de atores onde, no centro, aparecem frequentemente os extensionistas rurais. Não apenas parece importante ampliar o sistema de ATER, como qualificar os agentes para atuar como

\footnotetext{
3 Nas compras da agricultura familiar para o PNAE é permitida a dispensa do processo licitatório tradicional (Lei $\left.n^{\circ} 8666 / 1993\right)$ e as compras podem ser realizadas por meio do instrumento de compra denominado chamada pública, desde que atendidos os preceitos constitucionais de legalidade, impessoalidade, moralidade, publicidade e eficiência e os preços estejam em conformidade com os preços médios praticados no mercado local (AMARAL, 2016).
} 
facilitares de novas redes. $O$ aprendizado organizacional demandado pelos mercados institucionais contribuiu para mostrar que é possível inovar neste sentido. Ao mesmo tempo, parece urgente resolver problemas básicos de infraestrutura rural: estradas, internet, telefonia, pequenas centrais de distribuição, estruturação das associações e pequenas cooperativas, sistemas de gestão... são pontos de estrangulamento que, nas condições atuais, não apenas bloqueiam novas estratégias de comercialização, mas dificultam a presença da agricultura familiar naquelas já existentes, inclusive nos mercados institucionais.

A Emater/RS, representada pela Unidade de Cooperativismo 4 (UCP) de Erechim-RS, teve sua inserção no processo de compras da agricultura familiar para o PNAE em Passo Fundo, mediante acesso de recursos do Ministério do Desenvolvimento Agrário (MDA), por meio de duas Chamadas Públicas de Ater em Cooperativismo. Esta iniciativa possibilitou a construção de estratégias para enfrentar as dificuldades existentes no âmbito local. $O$ objetivo deste projeto de cooperativismo empreendido pela Emater/RS era qualificar a gestão do PNAE e possibilitar o acesso das cooperativas da agricultura familiar no mercado da alimentação escolar.

Segundo o relato dos representantes da Emater, o objetivo da iniciativa da Emater/Erechim era centralizar as demandas de aquisições das escolas estaduais em uma Chamada Pública Unificada articulada pela $7^{\text {a }}$ CRE. Com isso cada uma das 39 escolas estaduais de Passo Fundo elaborava a lista de produtos que precisaria adquirir e a encaminhava à CRE. A Coordenadoria, por sua vez, juntava todas as demandas por produtos da agricultura familiar e organizava uma Chamada Pública Unificada. Os agricultores familiares, individualmente ou por meio de suas cooperativas, habilitavam-se como fornecedores em apenas uma chamada, articulada pela $7^{\mathrm{a}} \mathrm{CRE}$, que repassava os produtos demandados individualmente pelas escolas.

A primeira inserção destas escolas nesta modalidade de Chamada Pública Unificada, via $7^{\text {a }} \mathrm{CRE}$, aconteceu no segundo semestre de 2014. No gráfico 1 pode-se observar, no período de 2013 a 2017, uma mudança de comportamento em relação a participação das aquisições da agricultura familiar no tocante ao volume de recursos destinados ao conjunto das escolas estaduais de Passo Fundo para aquisição de alimentação escolar.

\section{Gráfico 1 - Percentual de compras da agricultura familiar para o PNAE nas Escolas Estaduais de Passo Fundo, 2013-2017.}

\footnotetext{
${ }^{4}$ Desde $\mathrm{o}$ ano de 2011 a Emater/RS possui sete UCPs no RS, as quais foram implementadas pelo Programa de Apoio ao Desenvolvimento do Cooperativismo Gaúcho. A UCP da Emater de Erechim atua em 72 municípios nas regiões administrativas de Erechim e Passo Fundo, no RS, buscando melhorias técnico-gerenciais para cooperativas, contemplando agricultores familiares associados. Evidencia-se as atividades desenvolvidas pela UCP junto aos empreendimentos da agricultura familiar no mercado institucional do Programa de Aquisição de Alimentos (PAA) e no PNAE, que é objeto de investigação deste estudo.
} 


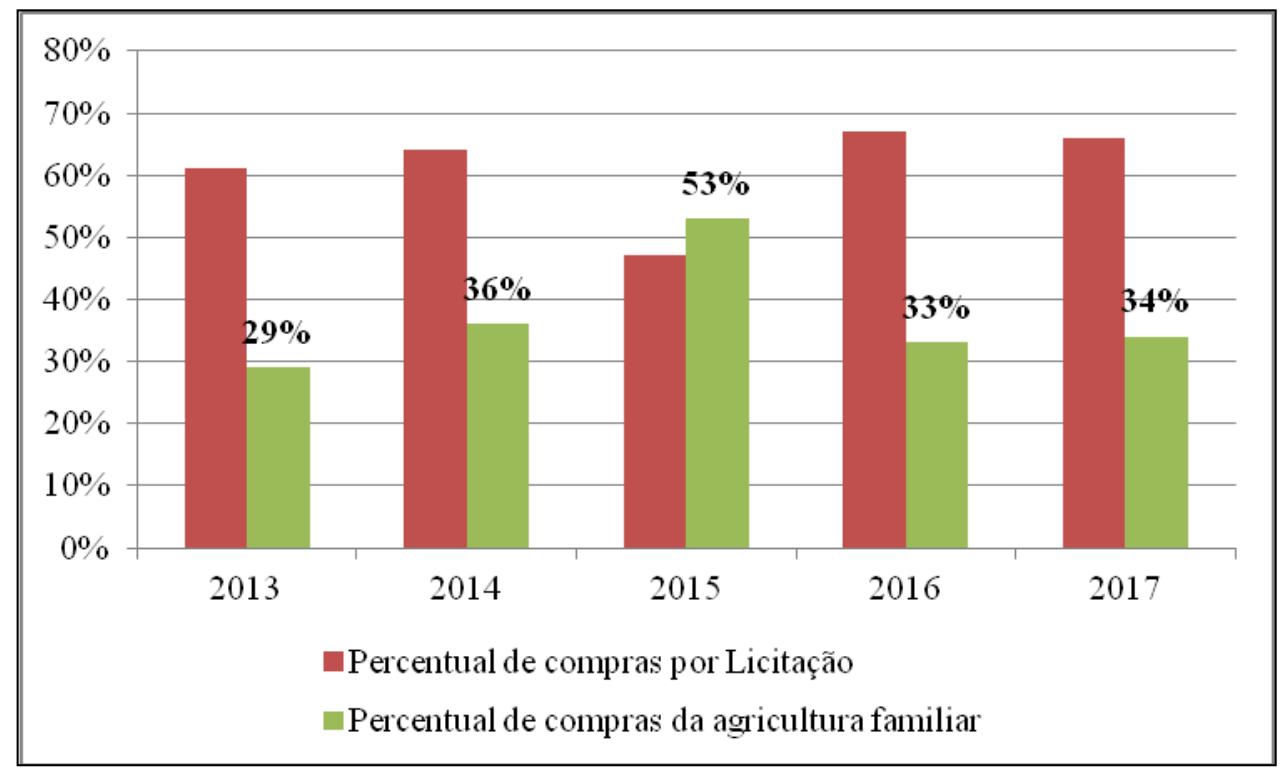

Fonte: Dados da pesquisa (2017).

Conforme pode ser observado no Gráfico 1, em 2013 o valor médio comprado pelas escolas estaduais de Passo Fundo em produtos da agricultura familiar atingiu o percentual de $29 \%$ do total transferido pelo FNDE. Em 2014, o primeiro ano da Chamada Pública Unificada (que englobou a demanda de todas as escolas estaduais do município), o percentual em compras da agricultura familiar atingiu 36\%, e em 2015 chegou ao índice de $53 \%$ em compras dessa categoria social. Estes dados evidenciam o aumento da participação de agricultores familiares no mercado institucional da alimentação escolar em Passo Fundo quando da utilização da Chamada Pública Unificada.

Pelo relato de entrevistados de vários segmentos de atores envolvidos na operacionalização do PNAE nas escolas públicas de Passo Fundo, a construção de um diálogo entre as cooperativas de agricultores familiares, a $7^{\text {a }}$ CRE e a UCP da Emater de Erechim alterou o caráter competitivo que existia entre os fornecedores para um cunho cooperativo, possibilitando a inclusão de diferentes categorias sociais, como agricultores familiares, assentados da reforma agrária e produtores de alimentos orgânicos. Também houve um aumento do percentual de compras da agricultura familiar e da diversidade da produção. Além disso, o trabalho desenvolvido em conjunto com os diferentes atores possibilitou a melhoria da qualidade da alimentação oferecida aos alunos, bem como oportunidades de renda e qualidade de vida para famílias que vivem no campo.

Este resultado converge com a constatação de Abramovay (2004, p. 47-48) ao afirmar que:

\begin{abstract}
o desenvolvimento dos mercados supõe formas localizadas, concretas de cooperação para as quais as ciências sociais contemporâneas voltam de maneira crescente seus estudos. Sob essa ótica, são muito mais que a soma cega e inconsciente de interesses privados, cujos protagonistas reúnem produzindo uma ordem que ninguém previu e sobre a qual ninguém tem controle. Eles envolvem algumas formas voluntárias de cooperação sem as quais nunca poderiam funcionar.
\end{abstract}

Nesta mesma direção Triches e Kilian (2016) identificaram que existe uma diferença no nível de intensidade das relações de parceria estabelecida entre os atores sociais envolvidos na operacionalização do PNAE nos distintos municípios que 
foram alvo de seus estudos. Mesmo constatando que em todos os municípios existam parceiros que auxiliam na implementação do artigo 14 da Lei n 11.947/2009, em alguns deles estes parceiros apresentam-se mais entrosados do que em outros. Neste sentido, a atuação da Emater teve uma contribuição decisiva na intensificação do nível de envolvimento entre os atores sociais ligados ao PNAE em Passo Fundo, garantindo melhorias e entendimento recíproco a fim de atender e compreender a legislação.

As escolas estaduais de Passo Fundo participaram das Chamadas Públicas Unificadas para compras da alimentação escolar via $7^{\text {a }} \mathrm{CRE}$ até o primeiro semestre de 2016. A partir do segundo semestre deste ano, o Governo do Estado do RS voltou a adotar a escolarização como forma de operacionalização do PNAE em sua rede estadual, modalidade em que a responsabilidade pelas compras e a administração da alimentação escolar passa a ser das escolas, por meio de uma Unidade Executora $\left(U^{5}{ }^{5}\right)$. Com esta mudança, a Chamada Pública Unificada em Passo Fundo deixou de ser feita pela $7^{\text {a }}$ CRE e cada escola voltou a fazer a Chamada Pública individualmente.

Esta mudança no formato da Chamada Pública enfraqueceu a relação dos agricultores familiares como fornecedores para o PNAE, como pode ser observado na manifestação de um dos entrevistados da Emater:

uma dificuldade do PNAE é que na rede estadual cada escola tem autonomia. Eles têm uma janela de tempo para fazer as chamadas. Mas aí você tem uma escola fazendo edital, por exemplo, de 01 a 15, outra do dia 02 ao dia 17 e outra fazendo dia 28. Essa é a primeira questão. A segunda dificuldade que me parece da rede estadual é a questão de logística e de pequena quantidade (de demanda de alimentos) nas escolas menores (E1).

Esta mudança gerou descontentamento tanto para as cooperativas fornecedoras de produtos da agricultura familiar, quanto para as próprias escolas. Para as cooperativas, o retorno para a escolarização passou a exigir um excesso de documentação a ser entregue em cada escola que elas têm interesse em participar da Chamada Pública, enquanto na modalidade Chamada Pública Unificada esta documentação era entregue uma só vez na $7^{\mathrm{a}} \mathrm{CRE}$. Para o representante de uma das cooperativas de agricultores familiares, "a Chamada Pública Unificada era uma forma mais rápida de desenrolar toda a documentação burocrática das Chamadas Públicas, agora precisamos fazer várias viagens a Passo Fundo para levar e assinar contratos das escolas estaduais" (AF1). Outro representante das cooperativas complementa:

a Chamada Pública Unificada facilitou muito, reduzia custos em papeis, autenticações em cartórios, pois era um único envelope para habilitação, era um único orçamento. A exclusão agregou maiores despesas ao participar das Chamadas Públicas, agregando um custo maior nos projetos e tornando certas vezes inviável a participação (AF2).

\footnotetext{
${ }^{5}$ Entidade privada formalmente constituída e sem fins lucrativos, representativa da comunidade escolar (Caixa Escolar, Associação de Pais e Mestres ou similar), responsável pelo recebimento dos recursos financeiros transferidos pela Entidade Executora, bem como pela prestação de contas à mesma (FNDE, 2013).
} 
Por parte das escolas, além de significar mais trabalho, esta mudança representou um retrocesso em relação aos avanços que até então haviam sido conquistados sob a articulação da $7^{\mathrm{a}}$ CRE.

Para os funcionários das escolas entrevistados, a Lei $n^{\circ} 11.947 / 2009$ e, especificamente, a suspensão da Chamada Pública Unificada que vinha sendo feita pela $7^{\mathrm{a}} \mathrm{CRE}$, por decisão unilateral do governo estadual, determinando que 0 processo de compra dos alimentos da agricultura familiar fosse realizado novamente a partir de cada escola, ocasionou dificuldades tanto para os funcionários das escolas quanto para as Cooperativas fornecedoras.

O volume de compras da agricultura familiar das escolas estaduais no ano de 2016, conforme se observou no Gráfico 1, reflete a mudança no mecanismo de compra de Chamada Pública Unificada, que vinha sendo realizada desde o segundo semestre de 2014, para o retorno à Chamada Pública individual em cada escola a partir do segundo semestre de 2016. Esta alteração no mecanismo de compra resultou em uma diminuição do percentual destinado aos fornecedores da agricultura familiar em relação aos recursos do FNDE (o qual era aproximadamente 53\% em 2015 para 33\% em 2016), mesmo considerando que no primeiro semestre de 2016 ainda tenha sido realizada a Chamada Pública Unificada.

Em termos de percentuais de compras da agricultura familiar para a alimentação escolar, conforme evidencia o Gráfico 1, o ano de 2017 seguiu a mesma tendência de 2016, alcançando o índice de aproximadamente 34\% dos recursos do FNDE, sugerindo, ao analisar as escolas estaduais em sua totalidade, que as mesmas realizam as compras da agricultura familiar procurando atingir o percentual de $30 \%$ dos recursos repassados pelo FNDE para cumprir a legislação. Estes números, confrontados com a realidade observada na pesquisa de campo nas onze escolas indicam que não existe um esforço sendo realizado por parte da gestão das escolas procurando aumentar as compras destes fornecedores, como ocorreu quando da realização das Chamadas Públicas Unificadas.

Dentre onze das escolas pesquisadas, nenhuma dispõe de um funcionário responsável somente pelo PNAE. Nas escolas pequenas, as quais têm em média até 400 alunos, quem cuida da alimentação escolar é a própria diretora ou alguma professora que, concomitantemente, desempenham outras funções pedagógicas e não possuem formação administrativa ou até mesmo habilidade para administrar o PNAE. Nas escolas maiores, onde existe uma funcionária para cuidar somente da parte financeira da escola, a mesma também passou a acumular a função de cuidar das compras para a alimentação escolar e de toda a parte burocrática necessária.

Conforme o relato da funcionária responsável pelo setor financeiro de uma das escolas, "no meu entendimento, nas escolas grandes precisaria de uma pessoa só para cuidar da papelada e outra para sair para a rua, para fazer os orçamentos" (D1).

Percebe-se que a imposição para as UExs, neste caso uma entidade ligada às escolas, administrarem os recursos do PNAE, incluindo o retorno da realização da Chamada Pública, gerou para os funcionários uma sobrecarga de trabalho e acúmulo de funções. Para Fernandes, Schneider e Triches (2016), a atuação do Estado, por meio do incentivo às compras públicas locais dos agricultores familiares, gera novas demandas, porém, boa parte dos gestores não está preparada para desempenhar estas atividades. 
Por outro lado, para os funcionários da $7^{\mathrm{a}} \mathrm{CRE}$, a responsabilidade da administração dos recursos da alimentação escolar (realização de Licitação, Chamada Pública, negociação com fornecedores, prestação de contas) é da UEx (escolas), ressaltando que a Lei da alimentação escolar determina que a gestão seja realizada desta forma, não podendo a coordenadoria assumir estas atividades.

Em relação ao retorno da realização de Chamada Pública Individual por escola, os extensionistas da Emater deste município evidenciam que:

\begin{abstract}
hoje, se o agricultor/cooperativa quer participar das compras de todas as escolas estaduais, são mais de 30 escolas, então tem que apresentar mais de 30 projetos, em 30 escolas diferentes. Se eu tenho a compra unificada, a cooperativa vai apresentar uma vez só; isso reduz as despesas e reduz 0 custo operacional, facilita a questão de recebimento. Nós temos que entender que quem participa como fornecedor do PNAE não é profissional de mercado e estes agricultores tiveram que aprender a conviver com nota, com a parte legal. Hoje ele precisa estar atento a edital, a chamada pública, a prazos, a tirar nota, a fazer controle.... É um contexto que não fazia parte do quotidiano deste agricultor. Mesmo a cooperativa precisou se organizar para isso (E1).

As cooperativas se reuniram e foram a Porto Alegre para ver se tinham como alterar isso, porque isso dificulta muito, porque assim, as cooperativas, cada uma delas tem que apresentar a documentação para cada uma das escolas. Isso gera, só em envelope de papel, um horror sabe, é muita trabalheira. Porque antes, as diretoras ou as responsáveis, elas vinham todas, a gente fazia geralmente ali no Sindicato dos Metalúrgicos, elas vinham todas ali com as demandas delas, colocavam as demandas delas e as cooperativas já dividiam, escola tal...escola tal...era tudo muito mais rápido e muito mais prático (E2).
\end{abstract}

A inexistência de regras claras com previsão de penalidades quando não se cumpre o mínimo de 30\% em aquisição de gêneros alimentícios da agricultura familiar previsto na Lei ${ }^{\circ}$ 11.947/2009 influencia negativamente nos resultados do programa. As escolas apresentam uma situação distinta em relação ao percentual de compras de produtos fornecidos por agricultores familiares. Enquanto algumas se empenham para comprar o máximo possível destes fornecedores, outras se esforçam para pelo menos garantir a exigência mínima e outras que sistematicamente adquirem menos de $30 \%$ estabelecidos em lei, sem nunca terem sido advertidas por descumprirem um dispositivo de lei.

\title{
4.3 Percepção dos atores sociais envolvidos na operacionalização do PNAE em Passo Fundo
}

A suspensão da Chamada Pública Unificada e a determinação do governo gaúcho para que este processo de compra dos alimentos da agricultura familiar fosse realizado a partir de cada escola após o segundo semestre de 2016, vem gerando dificuldades tanto para os funcionários das escolas, quanto para as cooperativas fornecedoras. Dentre as escolas pesquisadas, nenhuma dispõe de um funcionário disponível apenas para atender as demandas do PNAE. Nas escolas pequenas, quem cuida das compras da alimentação escolar é a própria diretora ou alguma professora e, nas escolas maiores, a mesma funcionária que cuida da parte financeira também 
acumula as funções relacionadas às compras para a alimentação escolar e de toda a parte burocrática envolvendo a operacionalização do PNAE.

Ao questionar os gestores das escolas sobre sua opinião em relação aos recursos destinados a aquisição dos alimentos, percebeu-se um consenso de que os valores são escassos e que é preciso fazer "milagre" para preparar uma refeição com um valor médio de $\mathrm{R} \$ 0,30$ por aluno, como se depreende em alguns trechos das entrevistas:

\begin{abstract}
os recursos são poucos, a gente faz milagre com a verba que recebe (D2). Os repasses tinham que sofrer a cada ano um aumento ao menos condizente com a inflação, porque nós continuamos aqui dentro com um número de alunos elevados, o dinheiro é o mesmo e as coisas ali fora subiram né. A gente vai fazendo como em casa, alguns milagres, fazendo render a comida, porque o dinheiro tem que dar para todos os dias úteis do mês, tem que dar (D3).

Com os recursos que recebemos fazemos milagre... Só para citar um exemplo, se você visse ontem de noite... a comida. A tia fez um panelão de arroz e carne com batatinha e cenoura; se você visse, era lindo de ver, eles agradeciam ela, eu fiquei encantada, até sequei toda a louça pra ela. Era um encantamento aquelas "crianças" comendo. E assim, nós não conseguimos comprar os 30\% da agricultura familiar, nós temos que justificar. O preço da agricultura familiar é mais alto do que o do mercado formal. Se nós formos pegar os $30 \%$ da agricultura familiar nós não conseguimos dar merenda o semestre todo (D4).
\end{abstract}

Constata-se que a individualização das compras por escola leva à fragmentação e à diminuição da demanda de alimentos produzidos localmente, pois cada escola faz as suas compras e isso diminui o interesse de agricultores individuais, e até mesmo das suas cooperativas, para participarem das chamadas públicas individuais pelo baixo valor que cada escola dispõe para gastar e pela pulverização das entregas, além, como já referido, da burocracia adicional que este processo descentralizado exige.

As gestoras das escolas relataram que os cardápios deveriam ser elaborados em conjunto com os funcionários das escolas, de acordo com a realidade de cada uma e levando em consideração os turnos (manhã, tarde ou noite) e não pela Seduc/RS, como ocorre. De todas as escolas pesquisadas, apenas uma relatou conseguir seguir o cardápio enviado pela Secretaria do estado; as demais relataram dificuldades, principalmente tendo em vista os recursos disponíveis e os gêneros alimentícios indicados nos cardápios.

Os fornecedores da agricultura familiar para a alimentação escolar de Passo Fundo estão organizados em Cooperativas de agricultores familiares, sendo mencionadas pelos gestores nas escolas pesquisadas cinco cooperativas que se destacam neste processo: a) a Cooperativa de Produção Agropecuária Terra e Vida Ltda (Coopervita), localizada no município de Tapejara (47 km de distância de Passo Fundo); b) a Cooperativa Central de Comercialização da Agricultura Familiar (Cecafes), de Erechim (76 km); c) a Cooperativa de Produção Agropecuária Cascata Ltda (Cooptar), e d) a Cooperativa Agropecuária e Laticínios Pontão Ltda (Cooperlat), ambas de Pontão (42 km); e, e) a Cooperativa Mista e de Trabalho Alternativo Ltda (Coonalter), sediada em Passo Fundo.

A Coonalter é a única cooperativa cuja sede fica em Passo Fundo, no entanto, os agricultores familiares associados a esta cooperativa são de outros municípios. 
Além das dificuldades inerentes à produção de alimentos orgânicos ou agroecológicos, a inexistência de associados de Passo Fundo também pode ser explicada pela pouca expressão da agricultura familiar neste município, como foi destacado na parte introdutória do trabalho. Esta cooperativa possui 25 anos de atuação e tem como foco principal a Feira Ecológica de Passo Fundo, oferecendo produtos como hortaliças, frutas e panificados.

A Coopervita tem sua sede no município de Tapejara e, diferente da Coonalter, possui em seu quadro social agricultores familiares de Passo Fundo. Segundo os extensionistas da Emater Municipal de Passo Fundo, esta cooperativa prioriza os produtos provenientes dos agricultores familiares de Passo Fundo, para atender as demandas da alimentação escolar das escolas situadas no próprio município.

Pela Resolução $n^{\circ} 4$, de 2 de abril de 2015, foi estabelecido que os projetos de venda habilitados devem selecionar os fornecedores obedecendo a seguinte ordem de prioridade: grupo de projetos de fornecedores locais sobre os demais grupos; grupo de projetos de fornecedores do território rural sobre o do estado e do país; e, por fim, grupo de projetos de fornecedores do estado sobre o do País (FNDE, 2015).

Outro ponto que foi evidenciado nas entrevistas nas escolas refere-se à aquisição de hortifrutigranjeiros, os quais são adquiridos, em sua maioria, da Cecafes de Erechim. Existem produtores de hortifrutigranjeiros em Passo Fundo, no entanto, conforme destacam os extensionistas da Emater municipal, os mesmos abastecem as feiras locais e não conseguem atender a demanda das escolas. Para os extensionistas da Emater municipal, a principal dificuldade dos agricultores locais é a logística para entrega dos produtos, devido existir 39 escolas estaduais, distribuídas em diferentes pontos da cidade e por estes produtos possuírem curto prazo de validade, devendo ser entregues semanalmente.

Desta forma, para estes agricultores familiares, as feiras locais são mais atrativas, pois o recebimento pela venda é imediato e as despesas com logística são menores. Em contrapartida, o mercado institucional da alimentação escolar de Passo Fundo vem sendo absorvido por cooperativas sediadas fora do município. Neste sentido, destaca-se a opinião do Extensionista da Emater sobre a baixa adesão de agricultores familiares de Passo Fundo no mercado institucional do PNAE:

não é que não existam produtores em Passo Fundo para atender a demanda da alimentação escolar, é que eles, talvez, ainda não conseguiram visualizar este mercado. Uma questão, que aí é uma avaliação minha, é um pouco diferente até, Passo Fundo é um mercado extremamente interessante, o mercado privado é interessante, daqui a pouco as agroindústrias daqui não tem tanto interesse em participar do mercado institucional porque tem espaço no mercado privado (E3).

Segundo Belik (2016b), os produtos fornecidos pelos agricultores familiares para o PNAE devem ser levados até o ponto de entrega, seja no depósito das prefeituras ou nas escolas, e as entregas devem ser feitas em pequenos lotes, podendo chegar, no caso de hortaliças, a duas ou até mesmo três vezes por semana. O autor ainda destaca que, após a entrega, os agricultores podem esperar em média até 60 dias para receber o valor dos produtos fornecidos.

$\mathrm{Na}$ visão das diretoras das escolas, os agricultores familiares individuais possuem dificuldades de se organizar para fornecer produtos para alimentação escolar devido a burocracia excessiva exigida para participar da Chamada Pública e 
as Cooperativas se constituem em uma oportunidade para eles participarem deste mercado. Fernandes, Schneider e Triches (2016) entendem que boa parte dos gestores da alimentação escolar ainda não consegue mensurar o potencial de produção e abastecimento que a agricultura familiar possui e de como este mercado pode trazer impactos positivos para o desenvolvimento local.

Em síntese, o que se aferiu sobre a operacionalização do PNAE nas escolas estaduais de Passo Fundo permite que se possa destacar que, de maneira geral, os relacionamentos entre os gestores locais do PNAE e os representantes da agricultura local ainda é incipiente, apesar de a aquisição de, pelo menos 30\% do valor repassado pelo FNDE, em produtos fornecidos por agricultores familiares, ter sido tornada obrigatória desde 2009. A forma escolarizada, priorizada pelo governo gaúcho para a operacionalização do programa, agrava esta dificuldade de relacionamento entre escolas demandantes e agricultores familiares fornecedores.

Por fim, é preciso mencionar que a experimentação das Chamadas Públicas Unificadas evidenciou melhorias importantes no relacionamento entre gestores do PNAE, via $7^{\text {a }} \mathrm{CRE}$, direções das escolas, cooperativas de agricultores familiares, com intermediação importante de técnicos da Emater/RS, e que estas relações criadas localmente permitiu uma participação maior da agricultura familiar de Passo Fundo e municípios do entorno, em especial pela articulação das cooperativas familiares.

Tanto os resultados positivos do período em que prevaleceu a Chamada Pública Unificada como processo de compra de produtos da agricultura familiar para as escolas estaduais de Passo Fundo, quanto o período atual, em que este mesmo processo voltou a ser conduzido em nível de cada escola, via Chamada Pública Individual, devem ser compreendidos como "construções sociais" (ABRAMOVAY, 2001) considerando que os atores envolvidos "estão imersos em sistemas concretos e contínuos de relações sociais" (GRANOVETTER, 2007), nem sempre convergentes. As possibilidades de potencializar a execução do PNAE nas escolas estaduais de Passo Fundo e de outros municípios passa pelo aprofundamento e qualificação dos relacionamentos entre os atores que participam localmente em diferentes níveis de operacionalização do programa para somar forças no enfrentamento com outros atores que igualmente interagem nos mesmos ambientes institucionais, defendendo não necessariamente os mesmos interesses locais ou regionais.

\section{Considerações finais}

As escolas estaduais de Passo Fundo ainda estão em processo de adaptação às novas diretrizes da alimentação escolar estabelecidas pela Lei n 11.947/2009. Desde a implementação da referida Lei até o ano de 2014, as escolas estaduais de Passo Fundo realizavam as compras da agricultura familiar a partir de Chamadas Públicas Individuais. Com o processo de inserção da UCP da Emater de Erechim, auxiliando na elaboração da Chamada Pública Unificada sob o comando da $7^{\text {a }}$ CRE (iniciada no segundo semestre de 2014) e do escritório municipal da Emater em Passo Fundo, contribuindo com a organização dos agricultores familiares, foram alcançados melhores resultados em termos de organização dos agricultores e também em termos de percentuais de compras destes fornecedores, ultrapassando os $30 \%$ determinados em lei ainda em 2014. 
A determinação da Seduc-RS de que, a partir do segundo semestre de 2016, cada escola estadual deveria realizar a Chamada Pública individualmente para adquirir alimentos da agricultura familiar, trouxe desvantagens para todos os atores sociais envolvidos com o mercado institucional da alimentação escolar neste município. Por parte das escolas gerou acúmulo de trabalho e até mesmo desvio de função, enquanto para as Cooperativas gerou excesso de burocracia, documentação adicional e dificuldades para mapear a demanda das escolas.

Com base no que se observou nas escolas estaduais em Passo Fundo, pode-se sugerir que a decisão unilateral do Governo do Estado do RS de eliminar a Chamada Pública Unificada por parte da CRE tenha criado dificuldades para que o PNAE possa potencializar as demandas da agricultura familiar pela demanda das escolas estaduais, não apenas no município de Passo fundo, mas em todo o estado do Rio Grande do Sul.

Fica claro que existe espaço para ampliar a participação da agricultura familiar enquanto fornecedor para o mercado institucional da alimentação escolar em Passo Fundo, para tanto as compras das escolas estaduais locais deveriam continuar centralizadas na $7^{\mathrm{a}} \mathrm{CRE}$, por meio da Chamada Pública Unificada. Isto facilitaria e potencializaria uma maior organização dos agricultores familiares locais e de suas organizações cooperativas, a partir do fortalecimento das relações com outros segmentos sociais, direta ou indiretamente envolvidos na execução do programa, considerando em especial as novas determinações vigentes com as transformações introduzidas em 2009, relacionadas com a maior inclusão de produtos de agricultores familiares locais.

A principal contribuição deste estudo consistiu em identificar que a realização de Chamadas Públicas Unificadas para o processo de compras de gêneros alimentícios da agricultura familiar para a alimentação escolar potencializa a inserção da agricultura familiar local/regional para o PNAE. Se existe um impedimento legal que imponha dificuldades para a continuidade deste processo de compra de forma unificada é fundamental que esta situação seja revista no âmbito do próprio FNDE, gestor nacional do programa.

Para estudos futuros sugere-se estender a pesquisa para as escolas de outras Coordenadorias Estaduais de Educação para aprofundar a compreensão sobre a participação da agricultura familiar no mercado institucional do PNAE no âmbito do Rio Grande do Sul a partir da demanda das escolas da rede pública estadual.

\section{REFERÊNCIAS}

ABRAMOVAY, R. Desenvolvimento e instituições: a importância da explicação histórica. In: ARBIX, G.; ZILBOVICIUS, M.; ABRAMOVAY, R. (Org.) Razões e ficções do desenvolvimento. São Paulo: UNESP, Edusp, 2001, p. 165-177.

. Entre Deus e o diabo: mercado e interação humana nas ciências sociais.

Tempo social, v. 16, n. 2, p. 35-64, nov. 2004. 
ALBRECHT, A. L.; et al. A Dinâmica de ATERS na Efetivação do PNAE no Município de Passo Fundo/RS. Disponível em:

<http://www.mda.gov.br/sitemda/sites/sitemda/files/user_img_1035/Oficial\%20Emat er\%20RS\%20\%28mercados\%20institucionais\%29_0.pdf>. Acesso em: 05 jun. 2017.

AMARAL, V. R. Potencialidades e limites da política de alimentação escolar na promoção da agricultura familiar. 2016. 102f. Dissertação (Mestrado em Desenvolvimento)- Universidade Regional do Noroeste do Estado do Rio Grande do Sul, ljuí.

BALEM, T. A. O Programa de Alimentação Escolar Brasileiro e a narrativa alternativa dos alimentos: convergências e desafios. Tese (Doutorado em Desenvolvimento Rural), Universidade Federal de Santa Maria, Santa Maria, 2015.

BASSO, D. Fundamentos teóricos e procedimentos metodológicos para a análise de processos reais de desenvolvimento. In: SIEDENBERG, D. R. (Org.).

Desenvolvimento sob múltiplos olhares. ljuí: Unijuí, 2012, p. 101-137.

BELIK, W. Agricultura familiar, políticas públicas e os novos mercados. In: TEO, C. R. P. A.; TRICHES, R. M. (Orgs.). Alimentação escolar: construindo interfaces entre saúde, educação e desenvolvimento. Chapecó: Unochapecó, 2016a, p. 65-88.

BELIK, W. Os limites para a expansão dos mercados locais. In: In: MARQUES, F. C.; CONTERATO, M. A.; SCHNEIDER, S. (Orgs.). Construção de mercados e agricultura familiar. Desafios para o desenvolvimento rural. Porto Alegre: UFRGS, 2016b, p. 183 $-205$.

BHASKAR, R. A realist theory of Science. London and New York: Routledge, 2008.

BRASIL. Lei no 11.947, de 16 de junho de 2009. Dispõe sobre o atendimento da alimentação escolar e do Programa Dinheiro Direto na Escola aos alunos da educação básica (...). Diário Oficial [da] União, Brasília, DF, 16 jun. 2009.

CHIBENI, S. S. A Inferência Abdutiva e o Realismo Científico. Cadernos de História e Filosofia da Ciência, v. 6, n. 1, p. 45-73, 1996.

DUFUMIER, M. Projetos de desenvolvimento agrícola: manual para especialistas.

Salvador: EDUFBA, 2007. 
FEE. Fundação de Economia e Estatística Siegfried Emanuel Heuser. Município: Passo Fundo. Disponível em: < http://www.fee.rs.gov.br/perfilsocioeconomico/municipios/detalhe/?municipio=Passo+Fundo>. Acesso em: 17 mar. 2017.

FERNANDES, P. F.; SCHNEIDER, S.; TRICHES, R. M. Identificação da oferta de produtos da agricultura familiar e da demanda pelo Programa de Alimentação Escolar das escolas estaduais do Rio Grande do Sul. In: In: TEO, C. R. P. A.; TRICHES, R. M. (Orgs.). Alimentação escolar: construindo interfaces entre saúde, educação e desenvolvimento. Chapecó: Unochapecó, 2016, p. 169 - 199.

FNDE. Fundo Nacional de Desenvolvimento da Educação. Resolução CD/FNDE n 26 de 17 de junho de 2013. Dispõe sobre o atendimento da alimentação escolar aos alunos da educação básica no âmbito do PNAE. Diário Oficial [da] União, Brasília, DF, 14 jun. 2013.

. Resolução $\mathbf{n}^{\circ} 4$ de 2 de abril de 2015. Altera a redação dos artigos 25 a 32 da Resolução/CD/FNDE n² 26, de 17 de junho de 2013, no âmbito do Programa Nacional de Alimentação Escolar (PNAE). União, Brasília, DF, 2 Abr. 2015.

Sobre o PNAE. Disponível em:

<http://www.fnde.gov.br/index.php/programas/alimentacao-escolar/alimentacaoescolar-apresentacao >. Acesso em: 17 nov. 2016.

Resolução CD/FNDE nº 01 de 08 de fevereiro de 2017. Disponível em: <http://www.fnde.gov.br/fnde/legislacao/resolucoes>. Acesso em: 17 mar. 2017. GIL, A. C. Métodos e técnicas de pesquisa social. São Paulo: Atlas, 2016.

GRANOVETTER, M. Ação econômica e estrutura social: o problema da imersão. RAEeletrônica - v. 6, n. 1, Art. 9, p. 2-42, 2007. Disponível em: <http://www.redalyc.org/articulo.oa?id=205114655006>. Acesso em: 11 out. 2017.

GRISA, C.; PORTO, I. Dez anos de PAA: as contribuições e os desafios para o desenvolvimento rural. In: GRISA, C.; SCHNEIDER, S. (Orgs.). Políticas públicas de desenvolvimento rural no Brasil. Porto Alegre: UFRGS, 2015, p. 161-200.

IBGE. Instituto Brasileiro de Geografia e Estatística. IBGE cidades.

Disponível em: < https://cidades.ibge.gov.br/v4/brasil/rs/passo-fundo/panorama/>. Acesso em: 07 jun. 2017. 
LOPES, I. D. Análise da operacionalização do programa nacional de alimentação escolar em escolas públicas de Passo Fundo - RS. 2018. 151f. Dissertação (Mestrado em Desenvolvimento Regional)- Universidade Regional do Noroeste do Estado do Rio Grande do Sul, ljuí.

MALUF, R. S. J. Segurança alimentar e nutricional. Petrópolis: Vozes, 2007.

MAZOYER, M.; ROUDART, L. História das agriculturas no mundo: do neolítico à crise contemporânea. [Tradução de Cláudia Ferreira]. São Paulo: Editora UNESP; Brasília: NEAD, 2010.

MINAYO, M. C. S. (Org). Pesquisa social: teoria, método e criatividade. Petrópolis: Vozes, 2016.

MORGAN, K.; SONNINO, R. Repensando a alimentação escolar: o poder do prato público. In: WORLDWATCH INSTITUTE. Estado do Mundo: transformando culturas do consumismo à sustentabilidade. Bahia: Ed. UMA, 2010.

NIEDERLE, P. A. Afinal, que Inclusão produtiva? A contribuição dos novos mercados alimentares. In: DELGADO, G. C.; BERGAMASCO, S. M. P. P. (Orgs.). Agricultura familiar brasileira: desafios e perspectivas de futuro. Brasília: Ministério do Desenvolvimento Agrário, 2017, p. 168-196.

ONU. Organização das Nações Unidas. ONU e Brasil trazem representantes de 12 países para conhecer alimentação escolar no ES. Disponível em:

$<$ https://nacoesunidas.org/onu-e-brasil-trazem-representantes-de-12-paises-paraconhecer-alimentacao-escolar-no-espirito-santo/>. Acesso em: 21 de nov. 2017.

PLOEG, J. D. Van der. Mercados aninhados recém criados: uma introdução teórica. In: MARQUES, F. C. et al. (Org.). Construção de mercados para a agricultura familiar: desafios para o desenvolvimento rural. Porto Alegre: Editora da UFRGS, 2016. p. 21-52.

POLANYI, K. A grande transformação. As origens da nossa época. Rio de Janeiro: Campus, 1980.

SCHNEIDER, S. Mercados e agricultura familiar. In: MARQUES, F. C. et al. (Org.). Construção de mercados para a agricultura familiar: desafios para 0 desenvolvimento rural. Porto Alegre: Editora da UFRGS, 2016, p. 93-140. 
. Agricultura familiar y mercados. Boletín de Agricultura Familiar para América Latina y el Caribe, n. 17, en.-mar. 2017, p. 5-7.

SEDUC-RS. Secretaria da Educação do Rio Grande do Sul. Alimentação Escolar. Disponível em: < http://www.educacao.rs.gov.br/alimentacao-escolar >. Acesso em: 05 jun. 2017.

SILVA NETO, B. Análise diagnóstico de sistemas agrários: uma interpretação baseada na Teoria da Complexidade e no Realismo Crítico. Desenvolvimento em Questão, v. 5, n. 9, p. 33-58, 2007.

. Agroecologia e análise econômica de sistemas de produção: uma abordagem baseada no materialismo histórico e dialético. Cerro Largo: UFFS, 2016. SOARES, F. V. et al. Demanda estruturada e a agricultura familiar no Brasil: o caso do PAA e do PNAE. Brasília: IPC-IG/WFP, 2013.

SONNINO, R.; SPAYDE, J; ASHE, L. Políticas Públicas e a construção de mercados: percepções a partir de iniciativas de merenda escolar. In: MARQUES, F. C.; CONTERATO, M. A.; SCHNEIDER, S. (Orgs.). Construção de mercados e agricultura familiar. Desafios para o desenvolvimento rural. Porto Alegre: UFRGS, 2016, p. 311329.

TERRA E SILVA, M.; NATIVIDADE, M. M. P.; JOAQUIM, N. F. A execução do Programa Nacional de Alimentação Escolar (PNAE) e a compra da agricultura familiar. In: ENCONTRO DE ESTUDOS ORGANIZACIONAIS DA ANPAD, 9, 2016, Belo Horizonte. Anais... Belo Horizonte: Anpad, 2016.

TCU. Tribunal de Contas da União. Cartilha para conselheiros do Programa Nacional de Alimentação Escolar (PNAE). Brasília: TCU, 2017.

TRICHES, R. M. Reconectando a produção ao consumo: a aquisição de gêneros alimentícios da agricultura familiar para o Programa de Alimentação Escolar. Tese (Doutorado em Desenvolvimento Rural), Universidade Federal do Rio Grande do Sul, Porto Alegre, 2010.

. Repensando o mercado da alimentação escolar: novas institucionalidades para o meio rural. In: GRISA, C.; SCHNEIDER, S. (Orgs.). Políticas públicas de desenvolvimento rural no Brasil. Porto Alegre: UFRGS, 2015, p. 161-200. 
TRICHES, R. M.; BACCARIN, J. G. Interações entre alimentação escolar e agricultura familiar para o desenvolvimento local. In: TEO, C. R. P. A.; TRICHES, R. M. (Orgs.). Alimentação escolar: construindo interfaces entre saúde, educação e desenvolvimento. Chapecó: Unochapecó, 2016, p. 89-109.

TRICHES, R. M.; KILIAN, L. Papel dos atores sociais na aquisição de produtos da agricultura familiar para a alimentação escolar em municípios paranaenses. Redes, v. 21, n. 3, p. 159-179, 2016.

WAGNER, D.; GEHLEN, I.; SCHULTZ, G. Agricultura familiar, políticas públicas e cidadania: conexões construídas a partir da operacionalização do Programa Nacional de Alimentação Escolar. Redes, v. 21, n. 3, p. 121-145, 2016.

David Basso. Doutor em Desenvolvimento, Agricultura e Sociedade pela Universidade Federal Rural do Rio de Janeiro (UFRRJ). Professor do Programa de Pós-graduação Stricto-Sensu em Desenvolvimento Regional da Unijuí. davidbasso@unijui.edu.br

Indaia Dias Lopes. Doutoranda em História no PPGH/UPF. Bolsista Prosuc/Capes. Mestra em Desenvolvimento Regional no PPGDR/Unijuí. Graduada em Ciências Econômicas pela Universidade Federal de Santa Maria (UFSM). indaia_lopes@yahoo.com.br

Volmir Ribeiro do Amaral. Mestre em Desenvolvimento no PPGDES/Unijuí e graduado em Filosofia pela Universidade Regional do Noroeste do Estado do Rio Grande do Sul (Unijui).volmirdoamaral@gmail.com

Como citar: BASSO, David; LOPES, Indaia Dias; AMARAL, Volmir Ribeiro do. Reflexões sobre a operacionalização do PNAE nas Escolas Estaduais de Passo Fundo (RS). Redes, Santa Cruz do Sul, v. 24, n. 1, p. 163-186, jan. 2019. ISSN 1982-6745. Disponível em: https://doi.org/10.17058/redes.v24i1.11272. 